\title{
Microsatellite based Genetic Divergence Study in Bread Wheat (Triticum aestivum L. em. Thell.)
}

\author{
Monu Kumar ${ }^{1,2}$, R.K. Sharma ${ }^{1} *$, G.P. Singh ${ }^{1,3}$ and Anima Mahato ${ }^{4}$ \\ ${ }^{1}$ Division of Genetics, ICAR-Indian Agricultural Research Institute, \\ New Delhi - 110 012, India \\ ${ }^{2}$ ICAR-Central Research Institute for Jute and Allied Fibres, Barrackpore - 700 120, India \\ ${ }^{3}$ ICAR-Indian Institute of Wheat and Barley Research, Karnal-132 001, India \\ ${ }^{4}$ ICAR-Indian Institute of Seed Science, Mau - 275103, India \\ *Corresponding author
}

Keywords

Bread wheat, Genetic diversity, SSR

markers, Molecular

characterization, DNA

fingerprints

Article Info

Accepted:

17 November 2018

Available Online:

10 December 2018

\section{A B S T R A C T}

A set of 45 polymorphic microsatellite markers, representing markers for almost each chromosome, was used for the assessment of genetic diversity in 35 genotypes of bread wheat. A total of 127 alleles were detected which ranged from 2 to 6 with an average allele number of 2.82 per locus. The PIC value of the 45 SSRs ranged from 0.08 to 0.50 with an average PIC of 0.30. Resolving power and Marker index of all 45 markers varied from 0.17 to 2.82 and 0.16 to 1.52 , respectively. Genome wise comparison of diversity recorded maximum genomic diversity in genome A with highest number of alleles per locus (2.95), PIC (0.31), RP (1.33) and MI (0.90). A comparative study on the basis of homeologous chromosomes revealed homeologous chromosome 1 had highest number of alleles per locus (3.0), PIC value (0.32), RP (1.40) and MI (0.92). The homeologous chromosomes 5 and 7 were found to be most conserved with low PIC, RP and MI. The dendrogram, prepared on the basis of similarity matrix using the UPGMA algorithm, delineated the all genotypes into three clusters with 13,11 and 11 genotypes in cluster I, II and III, respectively. The results demonstrate the utility of microsatellite markers for detecting polymorphism and for estimating genetic diversity in wheat.

\section{Introduction}

Wheat is a key global commodity in terms of acreage that fetches maximum tradable value in global market. It is an important component of staple in household diet and fulfills a major portion of total global calories, proteins and micronutrients that support growth and development. As a staple food, it is used in a variety of products that ranged from multipurpose flour used to make freshly baked breads or cookies to processed products such as canned soups that may contain wheat starch as a thickener (www.statistica.com). Wheat is being grown in diverse climatic regimes and can withstand wide temperature range as well as moisture availability. But with an increase in global average temperature wheat crop are being exposed to high temperature stresses during flowering and grain filling stage that 
significantly reduces its yield. So, in this era of greater climate concern, the major focus lies on sustainable wheat production and genetic manipulation is the best way to boost up wheat production. Therefore, assessment of genetic diversity is the pre-requisite for any breeding strategy aimed towards the improvement of wheat productivity.

Genetic diversity is the key pillar of biodiversity and diversity within species, between species and of ecosystem and, from the very beginning of agriculture, this natural genetic variability within crop species has been exploited to meet subsistence food requirement. Evaluation of genetic diversity levels among adapted, elite germplasm can provide predictive estimates of genetic variation among segregating progeny for pureline cultivar development (Salem et al., 2008).

Molecular markers technology is the one possible approach to understand the genetic diversity which is independent of environment effects. Molecular markers based on polymerase chain reaction (PCR) methods, such as simple sequence repeats (SSRs) or microsatellites, have become important genetic markers in a wide range of crop species, including wheat. SSR markers are abundant, dispersed throughout the genome, and show higher levels of polymorphism than other genetic markers (Roder et al., 1995, Al Khanjari et al., 2007). These features, coupled with their ease of detection, make them ideal for identifying and distinguishing between accessions that are genetically very similar (Joshi et al., 1993).

Various studies have used SSR markers to investigate genetic diversity in cultivated hexaploid wheat genotypes of $T$. aestivum $\mathrm{L}$ (Devos and Gale, 1992; Chao et al., 1989; Plaschke et al., 1995; Powell et al., 1996; Schloetterer et al., 1991). The present investigation was designed to use genomic
SSR markers in assessing level of genetic diversity in bread wheat.

\section{Materials and Methods}

\section{Plant material}

The present investigation was carried out using 35 wheat genotypes representing a range of phenotypic variation. The experimental material included released varieties for different production conditions of various zones and pre-released advance lines developed at Indian Agricultural Research Institute, New Delhi and other esteemed institutes of India (Table 1). Molecular work was undertaken in Molecular Lab at NRCPB, Pusa, New Delhi.

\section{SSR marker and PCR analysis}

Total genomic DNA was isolated from $5 \mathrm{gm}$ of fresh young leaf tissue, collected from five one-month old bulked leaf samples following the CTAB procedure (Plaschke et al., 1995). A set of 77 Simple Sequence Repeats (SSR) markers, representing all three genomes, were used for molecular characterization of wheat genotypes. In order to ensure whole genome coverage microsatellite repeats were selected from each arm of 21 chromosomes, including 'Xgwm', 'Xwmc' and 'Xbarc' markers which represent the organization responsible for identification and characterization of these markers. The PCR amplification was performed with a final volume of $15 \mu \mathrm{l}$ containing $50 \mathrm{ng}$ DNA of genomic DNA. Amplification products were resolved on $3 \%$ metaphor agarose gel and the electrophoresed DNA samples were visualized, photographed and documented using a UV Trans-illuminator geldoc system. The allele sizes were determined by comparing with $50 \mathrm{bp}$ ladder. Out of 77 SSRs, 45 markers (26 'Xgwm', 14 'Xwmc' and 5 'Xbarc' markers) showed polymorphism and were subjected to further 
analysis. The list of 45 polymorphic markers has been presented in Table 2 .

\section{SSR data analysis}

Fragments amplified by microsatellite primers were scored as presence (1) or absence (0) relative to the molecular weight standard (100bp DNA ladder). Resolving Power (RP) of a primer was calculated as the sum of "band informativeness" of all bands produced by a primer (Prevost and Wilkinson 1999).

Band informativeness $(I b)=1-(2 x \mid 0.5-$

Where, ' $p$ ' is the proportion of accession containing the band.

Resolving Power of the primer (RP) is represented as $\mathrm{RP}=\sum \mathrm{Ib}$.

The polymorphic information content, generally refers to the ability of a marker to establish polymorphism in the population based on the number of alleles detected and their distribution frequency, of each primer was determined according to the marker index of Powell et al., (1996).

$P I C=1-\sum\left(p i^{2}\right)$

Where, 'pi' is the frequency of $i^{\text {th }}$ allele and ' $\mathrm{n}$ ' is the number of genotypes.

Marker index (MI) is a statistical parameter used to estimate the total utility of the maker system and is estimated as the product of polymorphic information content (PIC) and effective multiplex ratio (EMR) (Cheknoskov and Artemyeva, 2015) as:

$M I=P I C x E M R$

Where,

$$
E M R=n_{p}\left(n_{p} / n\right)
$$

Genetic dissimilarity indices were calculated by using simple matching coefficients. Principle coordinate analysis (PCoA) and the cluster analysis based on unweighted neighbor-joining method were undertaken using DARwin5.0 (Perrier et al., 2003).

\section{Results and Discussion}

\section{Assessment of genetic diversity}

Genetic diversity of 35 wheat genotypes was carried out with 77 SSR markers of which 45 markers (26 'Xgwm', 14 'Xwmc' and 5 'Xbarc' markers) showed polymorphism. The 45 markers were selected from all seven linkage group that ensures the uniform coverage for whole wheat genome. The 45 polymorphic markers identified a total of 127 alleles. The number of alleles per SSR marker ranged from 2 to 6 with an average of 2.82 . Out of 45 microsatellites, 21 were biallelic, 15 were triallelic, 7 were tertrallelic and 2 markers viz., Xwmc684 and Xgwm264, were hexallelic. The 45 polymorphic markers identified 35 rare (frequency $<20 \%$ ) and 9 unique alleles. Information regarding the number of alleles detected per SSR locus, polymorphism information content (PIC), resolving power (RP), and marker index (MI) is given in Table 2 .

This revealed the occurrence of many alleles with frequencies less than 0.20 there by implying that these alleles have occurred in less than seven genotypes out of the 35 genotypes. One marker (Xgwm 130) revealed one allele, 17 markers revealed two alleles, 19 markers revealed three alleles, two markers revealed four alleles and one marker (Xgwm 264) detected five alleles. Number of alleles per marker ranged from 1 to 5 with an average value of 2.67 alleles per marker revealing the polymorphic ability of SSR markers. Salem et $a l$. , (2008) also reported 2 to 7 with an average of 3.2 alleles per marker with 48 SSR markers 
in wheat. The level of polymorphism observed in this study is lower than reported by other research workers in case wild wheat lines or landraces (Buchanan et al., 1994; Rohlf, 2000; Schloetterer, 1991) due to the considerable amount of natural out crossing that occurs in those genotypes. However, Salem et al., (2008) opined that the cultivars developed through repeated inbreeding are likely to show lower diversity. In the present investigation also majority of the genotypes developed through pedigree method.

The PIC value for 45 SSR primer pairs ranged from 0.08 in xgwm595 to 0.50 in wmc169 and barc146. The wide range of PIC value indicated that the locus specific PCR based microsatellite markers were quite informative. The average PIC value was recorded to be 0.30. However, this observed PIC range is lower than the range reported by Prevost and Wilkinson (1999), Kara et al., (2017) but comparable with the findings of Tomar et al., (2009). The mean PIC value estimated across all SSR loci was 0.30 . Twenty one primers (8 Xwmc, 10 Xgwm and 3 Xbarc markers) showed greater PIC value than mean suggesting the suitability of these markers in wheat diversity assessment. The RP values of the markers ranged from 0.17 (Xgwm595) to 2.82 (Xbarc146) with an average RP value across the loci 1.28. The Marker index (MI) value was calculated for all markers which ranged from 0.21 in $\mathrm{Xgwm} 205$ to 1.52 in Xgwm340 with an average MI value of 0.86 across the loci.

Genome wise genetic diversity assessment with 21, 26 and 13 markers from A, B and D genome identified highest number of alleles per locus in case of A genome (2.95) followed by $\mathrm{D}$ genome (2.62) and B genome (2.27) respectively (Table 3). $\mathrm{F}$ found highest number of allele per locus in A genome (7.17) followed by B genome (5.86) and least by D genome. The PIC value was also recorded to be highest in A genome (0.31). However, B and D genome had 0.25 and 0.30 PIC. RP also showed similar trend. The highest RP of 1.33 was recorded in A genome followed by 1.21 and 1.02 in case of $\mathrm{D}$ and $\mathrm{B}$ genome, respectively. Genome A also had highest $\mathrm{MI}$ (0.90) followed by D genome (0.79), whereas B genome shown lowest MI value of 0.69.

The Homoeologous chromosomes 1 showed highest number of allele per marker (3.0) followed by chromosome 6 (2.33) and 4 (2.29), respectively. The PIC value (0.32), RP (1.40) and MI (0.92) were also highest in case of homeologous chromosome 1 . However, the PIC value, RP and MI value were low for homeologous chromosome 5 and 7 suggesting that these two chromosomes are either highly conserved or they may carry factors for important characters and any occurrence of any large variation or mutation occurring in these chromosomes might lead to the death of plants.

\section{Genetic similarity analysis using UPGMA and principle co-ordinate analysis}

Unweighted Pair Group method with Arthmetic Averages (UPGMA) cluster analysis was performed based on Jaccard"s similarity coefficient matrices derived from SSR markers and a denodgram of 35 wheat genotypes was constructed (Fig. 1). The 35 genotypes were grouped into three clusters with 13, 11 and 11 genotypes in cluster I, II and III, respectively. Based on similarity coefficient each cluster is further divided into two major sub-clusters. The two subclusters of cluster I contain 4 and 9 genotypes. Likewise, the two subclusters of cluster II had 3 and 8 genotypes and in case of cluster III the number was 5 and 6 . The Jaccard's dissimilarity coefficient varied from 0.24 to 0.66 exhibiting the presence of wide amount genetic variability among the genotypes. The dissimilarity coefficient was highest between CL3183 and HD2733 however, it was lowest between DBW14 and DL788-2 (Fig. 3). 
Table.1 Details of experimental materials

\begin{tabular}{|c|c|c|c|}
\hline S.N. & Genotype & Pedigree/Parentage & Developing center \\
\hline 1 & HD 2997 & BOW//HD 2285//HD2444 & IARI, New Delhi \\
\hline 2 & CL 3104 & HD 2883/ CL 1603 & IARI, New Delhi \\
\hline 3 & CL 3119 & HD 2878/ HD 2891 & IARI, New Delhi \\
\hline 4 & C 306 & REGENT19473*CHZ//2*C591/3/P19/C281 & HAU, Hisar \\
\hline 5 & MP 4010 & ANGOSTURA 88 & Gwalior \\
\hline 6 & CL 3198 & SUNSU/CHIBIA & IARI, New Delhi \\
\hline 7 & CL3108 & DW 1272/HD 2307 & IARI, New Delhi \\
\hline 8 & HD 2643 & VEE 'S'/HD 2407/HD 2329 & IARI, New Delhi \\
\hline 9 & CL 3178 & DW 1293/CL 1497 & IARI, New Delhi \\
\hline 10 & HD 2733 & ATILLA/3/TUI/CARC//CHEN/CHTO/4/ATILLA & IARI, New Delhi \\
\hline 11 & CL 3176 & HD 2877/CL1465 & IARI, New Delhi \\
\hline 12 & PBW 343 & ND/VG/9144//KAL/BB/3/YACO 'S'/4/VEE\#5 'S' & PAU, Ludhiana \\
\hline 13 & KUNDAN & TANORI71/NP890 & IARI, New Delhi \\
\hline 14 & DL 788-2 & K7537/HD2160/HD2278//L24/K4.14 & IARI, New Delhi \\
\hline 15 & CL 3146 & HW 1085/ DW 1302 & IARI, New Delhi \\
\hline 16 & DBW 17 & CMH 79A.95/3*CNO 79/RAJ 3777 & IIWBR, Karnal \\
\hline 17 & HD 3016 & PBW65/2*PASTER & IARI, New Delhi \\
\hline 18 & HD 2932 & KAUZ/STAR/HD 2643 & IARI, New Delhi \\
\hline 19 & CL 3190 & HD 2824/DW 1285 & IARI, New Delhi \\
\hline 20 & HD 2864 & K7537/HD2160/HD2278//L24/K4.14 & IARI, New Delhi \\
\hline 21 & PBW 590 & WH594/RAJ3814//W485 & PAU, Ludhiana \\
\hline 22 & HD 2894 & TURACO/PRINIA/DL 788-2/DW 871 & IARI, New Delhi \\
\hline 23 & CL 3153 & HW 5015/ CL 1556 & IARI, New Delhi \\
\hline 24 & PBW 373 & ND/VG9144//KAL/BB/3/YACO “S”/4/VEE \# 5 'S' & PAU, Ludhiana \\
\hline 25 & CL 3144 & CL 1509/ UP 2571 & IARI, New Delhi \\
\hline 26 & CL3106 & NG 8675/ METSO & IARI, New Delhi \\
\hline 27 & WR 544 & K. SONA/HD1999//HD2204/3/DW38 & IARI, New Delhi \\
\hline 28 & HD 2967 & ALD/COC//URES/HD $2160 \mathrm{M} / \mathrm{HD} 2278$ & IARI, New Delhi \\
\hline 29 & CL 3125 & HD 2687/ CL 1525 & IARI, New Delhi \\
\hline 30 & HD 2189 & HD 1963/HD1931 & IARI, New Delhi \\
\hline 31 & CL 3171 & HD 2643/ CL 1556 & IARI, New Delhi \\
\hline 32 & L 512 & HD 2877/CL 1567 & IARI, New Delhi \\
\hline 33 & CL 3183 & CL 1449/CL 1603 & IARI, New Delhi \\
\hline 34 & DBW 14 & RAJ3765/PBW343 & IIWBR, Karnal \\
\hline 35 & CL3118 & HD 2824/DW 1299 & IARI, New Delhi \\
\hline
\end{tabular}


Table.2 Number of alleles detected PIC, RP, HI and MI of all SSR markers

\begin{tabular}{|c|c|c|c|c|c|c|}
\hline S.N. & SSR Marker & Chromosome & Alleles & Average PIC & $\mathbf{R P}$ & MI \\
\hline 1 & xgwm282 & $7 \mathrm{~A}$ & 3 & 0.23 & 0.83 & 0.70 \\
\hline 2 & barc59 & $2 \mathrm{D}, 5 \mathrm{~B}$ & 3 & 0.49 & 2.63 & 1.48 \\
\hline 3 & barc70 & $4 \mathrm{~A}, 7 \mathrm{~A}, 7 \mathrm{D}$ & 3 & 0.37 & 1.44 & 1.10 \\
\hline 4 & barc105 & $3 \mathrm{~A}, 4 \mathrm{D}, 7 \mathrm{~A}, 7 \mathrm{D}$ & 4 & 0.25 & 1.31 & 0.99 \\
\hline 5 & wmc216 & $1 \mathrm{D}$ & 2 & 0.26 & 0.83 & 0.53 \\
\hline 6 & wmc597 & $1 \mathrm{~B}, 2 \mathrm{~B}, 3 \mathrm{~B}, 4 \mathrm{~A}, 6 \mathrm{~B}, 7 \mathrm{~B}$ & 2 & 0.28 & 0.74 & 0.56 \\
\hline 7 & wmc59 & $1 \mathrm{~A}, 1 \mathrm{~B}, 6 \mathrm{~A}$ & 3 & 0.31 & 1.35 & 0.93 \\
\hline 8 & wmc169 & $3 \mathrm{~A}$ & 3 & 0.50 & 2.72 & 1.49 \\
\hline 9 & barc146 & $6 \mathrm{~A}, 6 \mathrm{~B}, 6 \mathrm{D}$ & 3 & 0.50 & 2.82 & 1.49 \\
\hline 10 & barc101 & $2 \mathrm{~B}, 3 \mathrm{~B}, 6 \mathrm{~B}$ & 3 & 0.30 & 1.35 & 0.90 \\
\hline 11 & xgwm335 & $5 B$ & 4 & 0.29 & 1.52 & 1.15 \\
\hline 12 & xgwm130 & $2 \mathrm{~B}, 7 \mathrm{~A}, 7 \mathrm{~B}$ & 3 & 0.35 & 1.61 & 1.04 \\
\hline 13 & xgwm132 & $6 \mathrm{~B}, 6 \mathrm{D}$ & 3 & 0.29 & 1.22 & 0.88 \\
\hline 14 & xgwm614 & $2 \mathrm{~A}, 2 \mathrm{~B}$ & 4 & 0.19 & 1.03 & 0.75 \\
\hline 15 & xgwm369 & $3 \mathrm{~A}$ & 4 & 0.29 & 1.77 & 1.16 \\
\hline 16 & xgwm205 & $5 \mathrm{D}$ & 2 & 0.10 & 0.22 & 0.21 \\
\hline 17 & xgwm121 & $5 \mathrm{D}, 7 \mathrm{D}$ & 2 & 0.13 & 0.28 & 0.26 \\
\hline 18 & xgwm120 & $2 \mathrm{~B}$ & 2 & 0.47 & 1.65 & 0.94 \\
\hline 19 & xgwm131 & $7 B$ & 2 & 0.47 & 1.64 & 0.94 \\
\hline 20 & xgwm349 & $2 \mathrm{D}$ & 2 & 0.24 & 0.56 & 0.48 \\
\hline 21 & xgwm285 & $3 \mathrm{~B}$ & 3 & 0.28 & 1.22 & 0.84 \\
\hline 22 & xgwm459 & $6 \mathrm{~A}$ & 4 & 0.31 & 1.72 & 1.25 \\
\hline 23 & xgwm337 & $1 \mathrm{~B}, 1 \mathrm{D}$ & 2 & 0.48 & 1.61 & 0.96 \\
\hline 24 & xgwm469 & $6 \mathrm{D}$ & 3 & 0.09 & 0.28 & 0.26 \\
\hline 25 & wmc 215 & $3 \mathrm{~A}, 5 \mathrm{~A}, 5 \mathrm{D}$ & 2 & 0.31 & 0.78 & 0.62 \\
\hline 26 & xgwm526 & $2 \mathrm{~A}, 2 \mathrm{~B}, 7 \mathrm{~A}, 7 \mathrm{~B}$ & 2 & 0.13 & 0.28 & 0.25 \\
\hline 27 & wmc737 & $6 \mathrm{~B}$ & 2 & 0.29 & 0.72 & 0.57 \\
\hline 28 & wmc219 & $4 \mathrm{~A}$ & 2 & 0.24 & 0.56 & 0.48 \\
\hline 29 & xgwm340 & $3 B$ & 4 & 0.38 & 2.11 & 1.52 \\
\hline 30 & wmc684 & $6 \mathrm{~A}$ & 6 & 0.22 & 1.83 & 1.33 \\
\hline 31 & xgwm372 & $2 \mathrm{~A}$ & 3 & 0.43 & 2.11 & 1.29 \\
\hline 32 & wmc497 & $4 \mathrm{~A}, 7 \mathrm{~A}$ & 2 & 0.42 & 1.22 & 0.84 \\
\hline 33 & wmc85 & $3 \mathrm{~B}$ & 3 & 0.41 & 1.78 & 1.24 \\
\hline 34 & xgwm297 & $7 B$ & 2 & 0.20 & 0.44 & 0.39 \\
\hline 35 & wmc11 & $3 \mathrm{~A}$ & 3 & 0.45 & 2.11 & 1.35 \\
\hline 36 & wmc 258 & $4 \mathrm{~A}, 5 \mathrm{~B}$ & 2 & 0.13 & 0.28 & 0.26 \\
\hline 37 & xgwm400 & $7 \mathrm{~B}$ & 2 & 0.13 & 0.28 & 0.26 \\
\hline 38 & xgwm304 & $5 \mathrm{~A}$ & 2 & 0.43 & 1.28 & 0.85 \\
\hline 39 & wmc 238 & $4 B$ & 4 & 0.36 & 2.32 & 1.45 \\
\hline 40 & xgwm595 & $5 \mathrm{~A}$ & 2 & 0.08 & 0.17 & 0.16 \\
\hline 41 & xgwm566 & $3 \mathrm{~B}$ & 2 & 0.47 & 1.50 & 0.93 \\
\hline 42 & xgwm264 & $1 \mathrm{~B}, 3 \mathrm{~B}$ & 6 & 0.25 & 2.12 & 1.49 \\
\hline 43 & xgwm533 & $3 B$ & 2 & 0.31 & 0.89 & 0.61 \\
\hline 44 & xgwm389 & $3 \mathrm{~B}$ & 2 & 0.24 & 0.61 & 0.48 \\
\hline 45 & wmc631 & $1 \mathrm{~B}, 3 \mathrm{D}$ & 3 & 0.34 & 1.72 & 1.02 \\
\hline \multicolumn{3}{|c|}{ Mean } & 2.82 & 0.30 & 1.28 & 0.86 \\
\hline
\end{tabular}


Table.3 Genetic diversity in different genome and homoeologous chromosome

\begin{tabular}{|c|c|c|c|c|c|c|}
\hline Genome & $\begin{array}{c}\text { No. of } \\
\text { markers } \\
\text { used }\end{array}$ & $\begin{array}{c}\text { Number } \\
\text { of alleles } \\
\text { detected }\end{array}$ & $\begin{array}{c}\text { Average } \\
\text { allele per } \\
\text { locus }\end{array}$ & PIC & $\begin{array}{c}\text { Resolving } \\
\text { Power }\end{array}$ & $\begin{array}{c}\text { Marker } \\
\text { Index }\end{array}$ \\
\hline $\mathbf{7}$ & 21 & 62 & 2.95 & 0.31 & 1.33 & 0.90 \\
\hline $\mathbf{A}$ & 26 & 59 & 2.27 & 0.25 & 1.02 & 0.69 \\
\hline $\mathbf{B}$ & 13 & 34 & 2.62 & 0.30 & 1.21 & 0.79 \\
\hline $\mathbf{D}$ & $\mathbf{6}$ & \multicolumn{7}{|c|}{ Homeologous chromosome } \\
\hline $\mathbf{1}$ & 6 & 18 & 3.00 & 0.32 & 1.40 & 0.92 \\
\hline $\mathbf{2}$ & 9 & 16 & 1.78 & 0.20 & 0.80 & 0.53 \\
\hline $\mathbf{3}$ & 15 & 18 & 1.20 & 0.14 & 0.60 & 0.39 \\
\hline $\mathbf{4}$ & 7 & 16 & 2.29 & 0.24 & 0.92 & 0.65 \\
\hline $\mathbf{5}$ & 8 & 12 & 1.50 & 0.15 & 0.38 & 0.30 \\
\hline $\mathbf{6}$ & 9 & 21 & 2.33 & 0.17 & 0.79 & 0.58 \\
\hline $\mathbf{7}$ & 10 & 12 & 1.20 & 0.15 & 0.41 & 0.29 \\
\hline
\end{tabular}

Fig.1 Cluster dendogram depicting genetic divergence among 35 wheat genotypes based on SSR markers

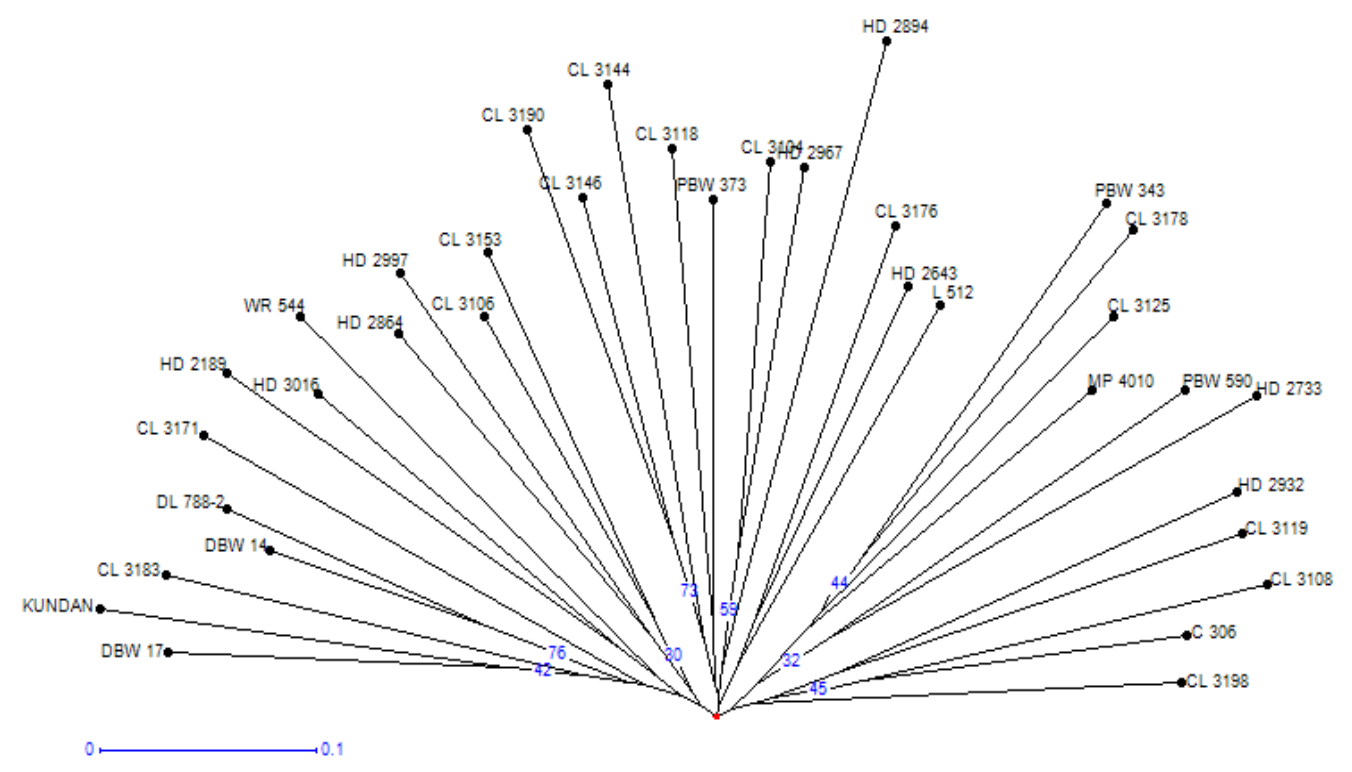


Fig.2 Principle coordinate analysis based on molecular data depicting genetic divergence of 35 wheat genotypes

\section{Factorial analysis: (Axes 1/2)}

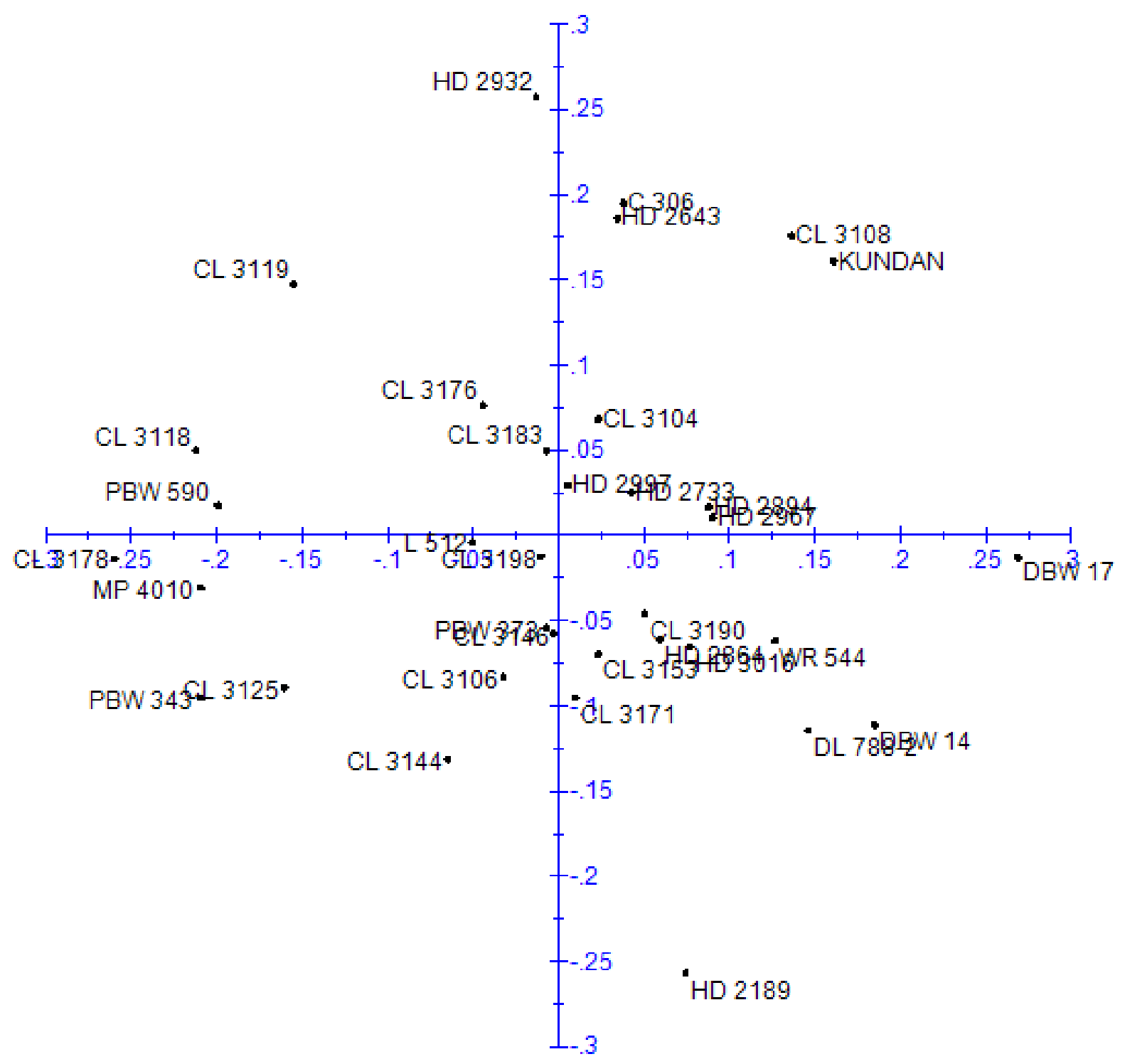




\section{Fig.3}

\section{Fig 3: SSR allelic profile among the 35 wheat genotypes. Genotypes numbers are according to Table 1.}

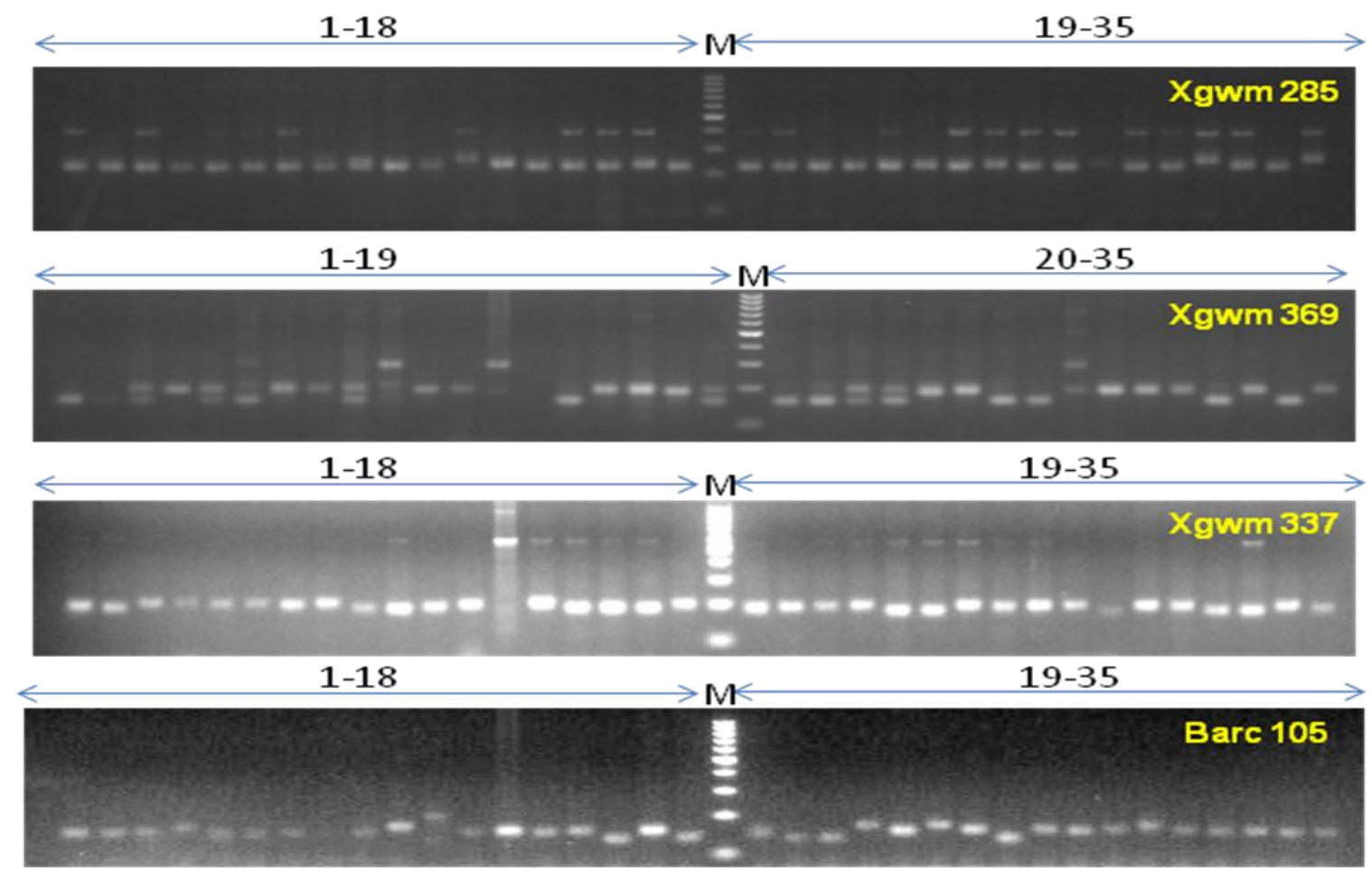

The results obtained from Principle coordinate analysis, as presented in Figure 2, classifies the 35 genotypes into four quadrates. A slight difference was observed between the results obtained through cluster diagram and principal co-ordinate analysis. The genotypes lying closer to each other in a co-ordinate are genetically more similar as compared to those located distantly.

The present study demonstrates the utility of SSR markers which can be profitably utilized in wheat for detecting polymorphism, tagging genes, (Prasad et al., 2000; Roy et al., 1999) and for estimation of genetic diversity. PIC values along with RP and MI of makers enabled finer distinction between wheat genotypes than routinely used PIC alone. Molecular characterization also facilitates selection of diverse genotypes and augment wheat improvement programme. Some genotypes possessing rare alleles for many different loci could be used for broadening the allelic diversity and the potential for cultivar improvement of wheat. Likewise, rare alleles can be identified using highly polymorphic single-locus SSR markers.

\section{Acknowledgement}

The first author is grateful to Indian Council of Agricultural Research (ICAR), New Delhi, for providing Junior Research Fellowship for Masters Degree programme.

\section{References}

Al Khanjari, S., Hammer, K., Buerkert, A. and Röder, M. S., 2007, Molecular diversity of Omani wheat revealed by 
microsatellites: I. Tetraploid landraces. Genetic Resources and Crop Evolution. 54: 1291-1300.

Buchanan, F. C., Adams, L. J., Littlejohn, R. P., Maddox, J. F. and Crawford, A. M., 1994, Determination of evolutionary relationships among sheep breeds using microsatellites. Genomics. 22: 397-403.

Chesnokov, Y. V. and Artemyeva, A. M., 2015, Evaluation of the measure of polymorphism information of genetic diversity. Agric Biol. 50(5): 571-578.

Chao, S., Sharp, P. J., Worland, A. J., Warham, E. J. and Koebne, R. M. D., 1989, RFLP-based genetic maps of wheat homoeologous Group 7 chromosomes. Theor. Appl. Genet.78: 495-504.

Devos, K. M. and Gale, M. D., 1992, The use of random amplified polymorphic DNA markers in wheat. Theor. Appl. Genet. 84: 567-572.

https://www.statistica.com

Joshi, C. P. and Nguyen H.T., 1993, RAPD (Random Amplified Polymorphic DNA) analysis based intervarietal genetic relationships among hexaploid wheats. Plant Science. 93: 95-103.

Kara, K., Rached-Kanouni, M., Debbabi, O. S. and Naceur, M. B., 2017, Genetic diversity of bread wheat genotypes (Triticum aestivum L.) revealed by agromorphological characteristics and microsatellite SSR markers. Inter. Jour. of Eng. Res. \& Tech. 6 (1): 178-182.

Kim, H. S. and Ward, R. W., 2000, Patterns of RFLP-based genetic diversity in germplasm pools of common wheat with different geographical or breeding program origins. Euphytica. 115: 197208.

Nagaoka, T. and Ogihara, Y., 1997, Applicability of inter-simple sequence repeat polymorphisms in wheat for use as DNA markers in comparison to RFLP and RAPD markers. Theor. Appl.
Genet. 94: 597-602

Perrier, X., Flori, A. and Bonnot, F., 2003, Data analysis methods. In: Hamon, P., Seguin, M., Perrier, X. and Glaszmann, J. C., (eds) Genetic diversity of cultivated tropical plants. Science Publishers Montpellier, Enfield, pp 4376.

Plaschke, J., Ganal, M. W., and Roder, M. S., 1995, Detection of genetic diversity in closely related bread wheat using microsatellite markers. Theor. Appl. Genet.91: 1001-1007.

Powell, W., Machray, G. and Provan, J., 1996, Polymorphism revealed by simple sequence repeats. Trends in Pl. Sci. 1: 215-222.

Prasad, M., Varshney, R.K., Roy, J.K., Balayan, H.S. and Gupta, P.K., 2000, The use of microsatellites for detecting DNA polymorphism, genotype identification and genetic diversity in wheat. Theor. Appl. Genet. 100: 584592.

Prevost, A. and Wilkinson, M. J., 1999, A new system of comparing PCR primers applied to ISSR fingerprinting of potato cultivars. Theor. Appl. Genet. 98: 107112.

Rohlf, F. J., 2000, NTSYS-pc: numerical taxonomy and multivariate analysis system, vers. 2.1. Exeter Publications, New York, USA.

Roy, J. K., Prasad, M., Varshney, R. K. and Balyan, H. S., 1999, Identification of a microsatellite on chromosomes $6 \mathrm{~B}$ and a STS on 7D of bread wheat showing an association with preharvest sprouting tolerance. Theor. Appl. Genet.99: 336340.

Salem, K. F. M., El-Zanaty, A. M. and Esmail, R. M., 2008, Assessing Wheat (Triticum aestivum L.) Genetic Diversity Using Morphological Characters and Microsatallite Markers. World Journal of Agricultural Sciences 
4 (5): 538-544.

Schloetterer, C., Amos, B. and Tautz, D., 1991, Conservation of polymorphic simple sequence loci in cetacean species. Nature. 354: 63-65.

Siedler, H., Messmer, M. M., Schachermayr, G. M., Winzeler, H., Winzeler, M. and Keller, B., 1994, Genetic diversity in European wheat and spelt breeding material based on RFLP data. Theor.
Appl. Genet. 88: 994-1003.

Spanic, V., Buerstmayr, H. and Drezner, G., 2012, Assessment of genetic diversity of wheat genotypes using microsatellite markers. Periodicum Biologorum 114 (1): 37-42.

Tomar, S. M. S. and Anabalgan, S., 2004, Characterization of cytoplasmic male sterile lines in wheat (Triticum aestivum L.). Indian J. Genet. 64: 189-195.

\section{How to cite this article:}

Monu Kumar, Sharma, R.K., Singh, G.P. and Anima Mahato. 2018. Microsatellite based Genetic Divergence Study in Bread Wheat (Triticum aestivum L. em. Thell.). Int.J.Curr.Microbiol.App.Sci. 7(12): 2222-2232. doi: https://doi.org/10.20546/ijcmas.2018.712.253 